\title{
Clinical Echocolpocsopy Features Of Cervical Cancer
}

\section{Dilnoza Isakova,}

Assistant, Faculty of advanced medical training and re-training, Department of obstetrics and gynecology, Andijan State Medical Institute, Uzbekistan.

\section{Zebiniso Inakova,}

Student, Andijan State Medical Institute, Andijan, Uzbekistan

Ranokhon Solieva,

Postdoctoral Scientific Researcher, Department Of The Chair Obstetrics And Gynecology №1, Andijan State Medical Institute, Uzbekistan

\section{Matkarimov Bakhtiyorjon,}

Ph.D., Academician, Associate Professor, Department Of General Surgery Of The Andijan State Medical Institute, Resident

Physician Of The 2nd Surgical Department Of The Clinic, Andijan State Medical Institute, Uzbekistan

Yorkinoy Farmankulova,

Assistant, Department Of Facultative Pediatric And Neonatology, Andijan State Medical Institute, Andijan, Uzbekistan

\section{Dilfuzahon Mamarasulova}

Md, Associate Professor, Head Of The Department Of Oncology And Medical Radiology, Andijan State Medical Institute, Uzbekistan
G Open aCcess

The American Journal of Medical Sciences And Pharmaceutical

Research

JULY 2020

Page No.: 123-129

Volume-II Issue-VII

PUBLISHED: 31 JULY 2020

www.usajournalshub.com/inde

x.php/TAJMSPR

Copyright: Original content from this work may be used under the terms of the

Creative Commons Attribution 4.0 licence.

\section{Abstract}

In recent years, doctors of ultrasonic diagnostics and cancers began to pay attention to the possibility to obtain information about the status of the cervix, especially with the aim of assessing the prevalence of tumor process, which is especially important in planning treatment. However, the information to date is fragmented and based on a small number of publications. However, to date not clearly developed sonographic criteria for cervical cancer, given the clinical course of the disease and possibilities of modern digital (digital) ultrasonic equipment, transvaginally, color echocardiography to better identify cervical pathology, which will improve timely, differential, and clarifying the diagnosis of cervical cancer.

Keywords: Echocolcoscopy, cervical cancer, a comprehensive clinical, laboratory, 
THE AMERICAN JOURNAL OF MEDICAL SCIENCES AND PHARMACEUTICAL RESEARCH

ISSN (e): 2689-1026

DOI: https://doi.org/10.37547/TAJMSPR/Volume02Issue07-16

ultrasonic, and morphological study

\section{Introduction}

It is no secret that women with malignant tumors of the cervix are received in specialized Oncology institutions in more than $60 \%$ of cases in advanced stages of tumor process, which is reflected in the unsatisfactory results of treatment, survival, and mortality. (Bohman Y. V.,1989). In this regard, the timely diagnosis of cervical cancer is an actual problem of modern Oncology. Currently, the diagnosis of cervical cancer is carried out comprehensively with the use of clinical, instrumental, and laboratory methods of research. Among them the special role of ultrasound diagnostics. The method has a number of advantages: high in formativeness, not invasiveness, safety, reusability, and holding under his control invasive procedures, allows the differential diagnosis between malignant, benign, and non-neoplastic diseases of the uterus, to assess the local, regional and overall prevalence of malignancy $[4,5,8]$. Until recently, most publications were focused on the possibilities of two-dimensional percutaneous (transabdominal) ultrasound in the diagnosis of neoplastic and non-neoplastic diseases of the genitals in women.

They are quite detailed and describes the son graphic characteristics of benign, nonneoplastic diseases of the uterus, appendages that allowed differential and clarifying the diagnosis of these diseases. The development of modern technologies of ultrasound diagnostics enabled the adoption of methods intracavitary (vaginal) ultrasound, which turned out to be more informative in women with severe subcutaneous fat of the anterior abdominal wall, with small-sized tumors of the organs of the genitalia. At the same time, the method transvaginal ethnography has its drawbacks. The method turned out to be less informative with large tumor conglomerates occupying the small pelvis $[1,4,5]$, this showed the feasibility of the integrated use of percutaneous (transabdominal) and transvaginal ultrasound imaging.

In recent years, methods for contrasting ultrasound of the uterus continue to develop, providing an assessment of the state of the uterine cavity in hyperplastic processes and endometrial cancer. Until recently, literary sources testified to the low informative value of ultrasound in the diagnosis of cervical pathology, including cervical cancer. However, publications of recent years indicate a high information content of ultrasound in assessing the degree of the local and general prevalence of cervical cancer $[1,4]$.

\section{Materials And Methods}

In this regard, we examined clinical and son graphic features of cervical cancer in 115 patients at the age of 21 to 70 years. According to the International classification TNM (who,1998). T1bNOM0 stage cervical cancer was diagnosed in $4(3,4 \%)$ patients; T2aNOMO - in $17(14.8 \%)$, T2bNOMO - 44(38,3\%) patients, T3aNOM0;T3N1M0 stage 21( 18,3\%), T3bNOM0;T3bN1M0 -у23(20,0\%) patients, and T4N0M0;T4N0M1; T4N1M1стадия diagnosed in $6(5,2 \%)$ patients. In all patients, the diagnosis was verified morphologically.

\section{Results And Discussion}


Analysis of the results of complex examination allowed to reveal that $25(21,7 \%)$ patients with cervical cancer at admission he complained of the presence of watery discharge from the genital tract, $87(75,7 \%)$ patients had bleeding, $24(20,9 \%)$ - pin $11(9,6 \%)$ stated that, acyclic bleeding. Most patients complained of weakness, malaise, pain in the abdomen, and lumbar region. 55(47,8\%) patients noted the development of the disease in the last 6 months. $32(27,8 \%)$ - during the year, the remaining $28(24,4 \%)$ patients in terms of more than a year. Only 14(12.2 percent) patients of cervical cancer were in menopause within 1-5 years or more.

Gynecological examination at 111 (96.5 percent) of patients had an increase in the size of the cervix due to the presence of a tumor of large size, with helophytic growth form tumors occurred in 55(47,8\%) patients, in 44(38.3 percent) - entophytic form, of these, $11(25,0 \%)$ patients the cervix was almost completely destroyed by the tumor, in 16(13.9 percent) diagnosed with a mixed form of growth of cervical cancer. In 44(38.3 percent) patients had parametrical infiltration not extending to pelvic bones with two sides, at $23(20,0 \%)$ - reaching to the bones of the pelvis with one hand. In $2(1.7 \%)$ patients showed signs of tumor invasion into the bladder. Signs of enlarged lymph nodes in the pelvis were in $2(1.7 \%)$ patients with an abdominal-vaginal examination, in 2 $(1.7 \%)$ signs of tumor invasion of the cervix into the rectum with the rectal abdominal murine study. However, the clinical and bimanual studies have not yielded satisfactory data on tumors of the cervix, the extent of the local and systemic dissemination of tumor process, that have been supplemented with data from other research methods (cystoscopy, barium enema, rentgenografija, CT, etc.), as well as comprehensive ultrasound examination.

Analysis of the results of complex ultrasound studies has shown that cervical cancer is typically a combination of direct and indirect sonographic signs. Direct signs directly caused by tumor formation of cervical cancer, and indirect - the spread of a tumor to nearby tissues and organs, as well as metastatic lesions of other organs and tissues.

The frequency of direct and indirect sonographic signs of cervical cancer are presented in table 1 and 2

\section{Table 1}

Frequency of direct sonographic signs of cervical cancer ( $p-115)$

\begin{tabular}{|c|c|c|c|}
\hline & Sonographic signs & Number of patients & $M+M \%$ \\
\hline 1 & $\begin{array}{l}\text { Size of the cervix } \\
\text { Enlarged } \\
\text { Not increased }\end{array}$ & $\begin{array}{c}111 \\
4\end{array}$ & $\begin{array}{c}96,5 \pm 1,6 \\
4,5 \pm 1,6\end{array}$ \\
\hline
\end{tabular}




\begin{tabular}{|c|c|c|c|}
\hline 2 & $\begin{array}{c}\text { Contours of the cervix } \\
\text { flat } \\
\text { uneven } \\
\text { clear } \\
\text { fuzzy }\end{array}$ & $\begin{array}{c}4 \\
111 \\
4 \\
111\end{array}$ & $\begin{array}{l}3,4 \pm 1,6 \\
96,6 \pm 1,7 \\
3,4 \pm 1,6 \\
96,6 \pm 1,7\end{array}$ \\
\hline 3 & $\begin{array}{l}\text { Cervix shape } \\
\text { Right } \\
\text { Wrong }\end{array}$ & $\begin{array}{c}4 \\
111\end{array}$ & $\begin{array}{l}3,5 \pm 1,7 \\
96,5 \pm 1,7\end{array}$ \\
\hline 4 & $\begin{array}{c}\text { Tumor localization } \\
\text { Along the front wall } \\
\text { Along the back wall } \\
\text { On the front and back } \\
\text { of the cervix }\end{array}$ & $\begin{array}{l}43 \\
37 \\
\\
35\end{array}$ & $\begin{array}{l}37,4 \pm 4,1 \\
32,2 \pm 4.1 \\
30,4 \pm 4,4\end{array}$ \\
\hline 5 & $\begin{array}{l}\text { Tumor structure } \\
\text { Homogeneous } \\
\text { Heterogeneous }\end{array}$ & $\begin{array}{l}41 \\
74\end{array}$ & $\begin{array}{c}35,7 \pm 4,46 \\
64,3 \pm 4,46\end{array}$ \\
\hline 6 & $\begin{array}{c}\text { The echogenicity of the } \\
\text { tumor } \\
\text { Hypoechoic } \\
\text { Hyperechogenic } \\
\text { Mixed }\end{array}$ & $\begin{array}{c}103 \\
3 \\
9\end{array}$ & $\begin{array}{c}89,6 \pm 2,62 \\
2,6 \pm 2,6 \\
7,8 \pm 3,9\end{array}$ \\
\hline 7 & $\begin{array}{l}\text { Cervical canal } \\
\text { Is being visualized } \\
\text { not visualized } \\
\text { thickened } \\
\text { deformed } \\
\text { expanded }\end{array}$ & $\begin{array}{c}105 \\
10 \\
88 \\
72 \\
10\end{array}$ & $\begin{array}{c}91,3 \pm 2,62 \\
8,7 \pm 2,6 \\
76,5 \pm 3,9 \\
62,6 \pm 4,5 \\
8,7 \pm 2,6\end{array}$ \\
\hline
\end{tabular}

As can be seen in table 4.5. Cervical cancer echographically was characterized by an increase in its size in $96.5 \%$ of cases. The size of the cervix ranged from $42 \times 39 \times 47 \mathrm{~mm}$ to $97 \times 71 \times 83 \mathrm{~mm}$. Moreover, the contours of the cervix were often uneven $(96,6 \%)$, fuzzy $(96,6 \%)$, and wrong $(96.5 \%)$. Two-dimensional ultrasound allowed us to determine the localization of the neoplastic process of the uterine cervix. And this was possible with greater certainty to say when combined percutaneous and transvaginal ultrasound. So cervical cancer tumor was localized on the anterior wall in $37.4 \%$ cases, rear $-32.2 \%$ on the front and back wall - at 30.4\%. Moreover, the more was the size of the tumor, and 
the distribution process occupies a large area and volume of the cervix.

In $4(3,5 \%)$ patients with stage $1 \mathrm{~B}$ cervical cancer, echographically hotbed of the tumor was better visualized with transvaginal echography in the form of a lesion of low echogenicity. A tumor with cervical cancer was more often hypoechoic $(89,6 \%)$, heterogeneous in structure (64.3 percent). Two-dimensional ultrasound allowed us to assess the condition of the cervical canal. So in $91,3 \%$ of cases, the cervical canal was visualized clearly throughout, and in $76,5 \%$ - it was unevenly thickened. Its thickness ranged from $6-12 \mathrm{~mm}$ with the strain (62.6 percent) and parts of the seal and expansion.

To illustrate the following clinical observation.

Sick Timofeeva O. I., 35 years old (history of the disease 639) admitted to the Department of Gynecological Oncology of the Andijan branch of the Republican scientificpractical medical specialized Oncology center with complaints of bloody discharge from the genital tract, lower abdominal pain.

From the anamnesis: considers himself sick for 3 years, received treatment on the inflammatory process appendages and STIs (sexually transmitted infections). Six months ago in a private clinic removes a polyp of the cervix, after which at this place formed an ulcer.

The words of the patient, the heredity are not burdened, bad habits deny. Pregnancies were 2, delivery-1, abortion-1. Appealed to the Tashkent region ontological dispensary for examination and treatment. On examination, the patient's condition is satisfactory. Of the internal organs, pathology was not determined. During the inspection of the external genitals are developed correctly.

In the mirrors cervix cylindrical shape, deformed by the presence of education located on the front lip size $2,5 \times 3 \mathrm{~cm}$, with a flat surface. The vaginal mucosa is pale pink. Watery discharge.

When vaginal study (PVS) the body of the uterus of normal sizes, dense consistency, without pain. The cervix is enlarged, deformed, dense consistency. Marked shortening of the arches to the right with parametrical infiltration not extending to pelvic bones. The parameters left free.

$\mathrm{X}$-rays from 02.03 .20 - from the lungs and heart revealed no pathology.SCC $-0,28$ $\mathrm{mg} / \mathrm{l}$ at norm $(0,16-1,5)$. Ultrasound from 02.03.20. The liver is located in the right upper quadrant; its size is not enlarged. The contours of the liver are smooth, clear. The angle of the right lobe is less than $75^{*}$, left $-45^{*}$. The structure of the liver is homogeneous. The vessels are viewed all over. The diameter of the portal vein $11 \mathrm{~mm}$. The diameter of the common bile duct is $4 \mathrm{~mm}$. the Gall-bladder oval-shaped, walls smooth, clear, thickness-2 $\mathrm{mm}$, Content homogeneous.

Kidneys - located in a typical place, the size of both kidneys was normal. Parenchyma and CHLS were unchanged.

In the pelvis behind the bladder visualized the uterus in position

anteflexion-versio, size $60 \times 47 \times 58 \mathrm{~mm}$, the contours of the body of the uterus is a smooth, clear structure of the myometrium homogeneous, endometrial $4 \mathrm{~mm}$, homogeneous ( 1 phase ). Cervix size $56 \times 42-51 \mathrm{~mm}$, with irregular, indistinct contours, the deformed, the structure is heterogeneous. On the anterior wall of the cervix is determined by education low echogenicity, without clear contours. The cervical canal is misshapen, uneven, thickened to $7 \mathrm{~mm}$. (Fig.4.6.) The appendages on the right - 
$30 \times 25 \times 28 \mathrm{~mm}$, left - 29x $26 \times 30 \mathrm{~mm}$ cavity turning diameters of $10 \mathrm{~mm}$. Inguinal / iliac lymph nodes were not visualized.

\section{Conclusion}

According to the ultrasound pattern typical of disease of the cervix. Cr. Colli uteri. Patients underwent a morphological examination of the tumor of the cervix, histology from 7.03.05.- keratinized squamous cell cervical cancer. Conducted laboratory research methods. General analysis of blood (from 02.03.05.) Hb-90 g/l, er. - $3.1 \times 10$ 12/l, CPU 0 , 9. leukocytes $4.8 \times 109 / \mathrm{l}$, platelets - $236.8 \times 109 / \mathrm{l}$, ESR $-44 \mathrm{~mm} / \mathrm{h}$.

Urinalysis (from 02.03.05.) protein - 0,033 \%, leukocytes $16-20$ insight. Blood biochemical parameters in the norm.

A comprehensive clinical, laboratory, ultrasonic, and morphological study has allowed establishing the diagnosis of Cr Colli uteri, T2 NOMO stage II, clinical group II. In colposcopy: the Tumor has a heterogeneous texture, visibly its growth over the mucosa. The surface growths bumpy, juicy, bleeding. Pathology painted red through her translucent blood vessels. In some parts of the external OS visible white-yellow the sores.

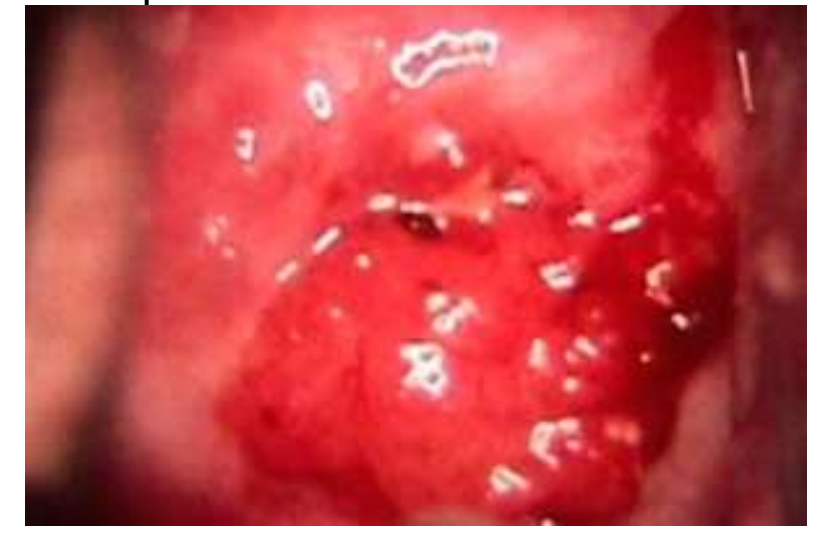

1. Colposcopic picture of cervical cancer

A sick planned course of combined radiation treatment.

\section{Acknowledgment}

As can be seen from the observations of clinical examination supplemented with twodimensional echocardiography has allowed more detail to determine the localization of the tumor process, to assess the state of nearby organs and tissues that formed the basis for selecting the correct tactics of treatment. Analysis of the results of complex ultrasound studies has shown that cervical cancer is typically a combination of direct and indirect sonographic signs. Direct signs directly caused by tumor formation of cervical cancer, and indirect - the spread of the tumor to nearby tissues and organs, as well as metastatic lesions of other organs and tissues.

\section{References}

1. Khachaturyan, A. R. Colposcopy. Foundations of algorithms of diagnostics and tactics of management of the cervical disease. Methodical recommendations / A. R. 
Khachaturyan, L. V. Martina. - M: N-L, 2011. - 24 c.

2. Diseases of the cervix. - M.: GEOTAR-Media, 2014. - $160 \mathrm{c}$.

3. Diseases of the cervix. Clinic, diagnostics, treatment. Textbook / T. V. Ovsyannikov and others - M.: Medpress-inform, 2013. - 173 c.

4. Diseases of the cervix. Modern methods of diagnosis and treatment. - M.: Publishing house of Nizhny Novgorod state medical Academy, 2006. - 112

5. Optimization in the treatment of cervical cancer // Problems of Biology and Medicine 2019, No. 4 (113) p. 47 http://pbim.uz/ (http://pbim.uz/) Mamarasulova D.Z., .M.Sh. Karimova, J.F. Togaev, D.K. Khudoyberdiev. //

6. Echographic and clinical features of cervical cancer // Doctor's herald №2 (94) 2020 // D. Z. Mamarasulova, D. B. Isakova, Kh. N. Negmatshaeva, A. F. Valid ova

7.Yao L, Yuan M, Yuan J, Zhou P, Mei L, Cheng J., Analysis of cervical human papillomavirus infection in 2300 women in Urumqi China. Medicine (Baltimore). 2018 Nov;97(45):e13206. DOI: 10.1097.

8. Yli-Kuha AN, Gissler M, Klemetti R, Luoto R, Hemminki E. Cancer morbidity in a cohort of 9175 Finnish women treated for infertility.// Hum Reprod.2012. -Apr.27. - (4): 1149-55. Epub 2012 Feb 16.

9. Zhang Y, Guo X, et al. Real-World Study of the Incidence, Risk Factors, and Prognostic Factors Associated with Bone Metastases in Women with Uterine Cervical Cancer Using Surveillance, Epidemiology, and End Results (SEER) Data Analysis. Med Sci Monit. 2018 Sep 12;24:6387-6397. doi: 10.12659/MSM.912071. 